\title{
Enhanced Education by Using Intelligent Agents in Multi-Agent Adaptive e-Learning Systems
}

\author{
Adriana ALEXANDRU, Eugenia TÎRZIU, Eleonora TUDORA, Ovidiu BICA \\ National Institute for Research and Development in Informatics, \\ 8-10 Marshal Averescu Blvd., Bucharest 1, RO-011455, ROMANIA \\ adriana@ici.ro,ginet@ici.ro,gilda@ici.ro,ovi@ici.ro
}

\begin{abstract}
The evolution of Web technologies has made e-Learning a popular common way to teach and learn both in school and non-school settings. This paper provides an education-oriented approach for building personalized e-Learning environments that focuses on putting the learners' needs in the centre of the development process. The proposed agentbased adaptive architecture extends Moodle platform in order to support instructional decisions and adaptive behaviour. The paper describes the characteristics, functions, and interactions of the agents which take part in each module of the adaptive architecture, as well as an intelligent agent for instructional decisions making. The aim of this agent is to collect information generated by the rest of agents and to provide the best personalised support for the final users, tutors and students, taking into account their attitudes towards the learning environment.
\end{abstract}

Keywords: Intelligent agents, adaptive e-Learning system, intelligent systems, user modelling, tutor modeling, Learning Content Management System, Moodle.

\section{Introduction}

The concept of intelligent agent is one of the most important concepts that have emerged in the field of computers since 1990. The technology that is based on agents is of particular importance in terms of humancomputer interaction. One primary characteristic that differentiate agents from an ordinary program, is that the agent must be autonomous [1]. Several definitions of agents include this characteristic:

- "Most often, when people use the term 'agent' they refer to an entity that functions continuously and autonomously in an environment in which other processes take place and other agents exist." [2];

- "A hardware or (more usually) a softwarebased computer system that enjoys the following properties: autonomy - agents operate without the direct intervention of humans or others, and have some kind of control over their actions and internal state; social ability - agents interact with other agents (and possibly humans) via some kind of agent-communication language; reactivity: agents perceive their environment and respond in a timely fashion to changes that occur in it; proactiveness: agents do not simply act in response to their environment, they are able to exhibit goal-directed behaviour by taking initiative" [3];
- "An agent is an encapsulated computer system that is situated in some environment and that is capable of flexible, autonomous action in that environment in order to meet its design objectives" [4];

- $\quad$ "An autonomous agent is a system situated within and a part of an environment that senses that environment and acts on it, in pursuit of its own agenda and so as to effect what it senses in the future" [5].

All definitions add some other characteristics, among which interaction with the environment is mentioned by most specialists.

Currently, there are many research works aimed at foundation, standardization and unification of different methodologies, tools, methods and techniques of agent-based software engineering, offering complete and effective theories for the development of such systems.

Most researchers view agents mainly as entities acting collectively alongside other agents, therefore the multi-agent system (MAS) paradigm is used. MAS is a collection of autonomous entities called agents, which interact with each other and with their environment in a cooperative or competitive way in order to achieve individual and group goals [6]. According to Wooldridge [7], the major advantages of MAS are: decentralized control, robustness, simple extensibility, expertise and common resources. 
The multi-agent models an interactive system through a collection of specialized agents that produce and react to stimuli existing in the system. In a multi-agent system, each agent theoretically, operates independently of the existence of other agents. For complete specification of a multi-agent system is necessary to define the knowledge and the internal behavior of agents and their interaction with others agents that coexist within a multiagent system.

"A Multi-Agent System (MAS) contains an environment, objects and agents (the agents being the only ones to act), relations between all the entities, a set of operations that can be performed by the entities and the changes of the universe in time and due to these actions" [8].

It is extremely difficult to give the definition of an intelligent agent; a comprehensive definition was given by J. Ferber [7] which considers that an intelligent agent is a physical or virtual entity that is capable of acting upon itself and its environment, which has a partial representation of this environment, which, in a multi-agent environment, can communicate with other agents and whose behavior is the result of his observations, his knowledge and his interactions with other agents.

A definition that underlines the aspect of making a program to be considered as an intelligent agent is given by Hayes-Roth. According to this "Intelligent agents continuously perform three functions: perception of dynamic conditions in the environment; action to affect conditions in the environment; and reasoning to interpret perceptions, solve problems, draw erences, and determine actions" [9].

The main problem faced by an intelligent agent is to decide which actions should be carried out in order to successfully fulfil the goals. The complexity of decision making process is affected by the properties of the environment. The agent receives stimuli from the environment and produces actions that affect the environment. Interaction is typically continuous.

Features as interactivity, autonomy, proactivity and learning make agents to be an interesting approach in implementing eLearning environments and provides flexibility for future extensions.
An e-Learning system should provide the requested information within a reasonable time, being sometimes difficult to achieve it by conventional search methods. The time consuming operations, as to search for information about a particular topic, can be left to competent agents. Intelligent agents for eLearning are autonomous software tools correlated to other software applications and databases running in a computer environment. The main function of an intelligent agent for eLearning is to help the user to interact with an application that presents a learning area.

The Intelligent Training Systems (ITS) are computer-based educational systems aimed at providing learning programs to each student in a flexible manner and to provide learners adaptive instruction and feedback. A number of successful evaluation of ITS sites [10] have demonstrated that such systems can be effective for improving learning by increasing motivation and performance of students, comparing with traditional methods.

\section{Intelligent Agents}

A relevant description of the intelligent agent concept is given by a list of features that it should have. In the scientific community there is no consensus on the importance of various features of agents; however, we can identify some features that an agent should fulfill in order that he may be called intelligent agent:

- Intelligence: ability to reason and learn; at a high level of intelligence, the agent will have to understand what the user wants and to plan the necessary means to achieve the purpose;

- Interactivity: the agent can respond to the following environmental components: people, hardware, other agents and software not belonging to the agents;

- Autonomy: "agents are able to act without human intervention or from other systems and to have control over their behavior and so on internal states" [11];

- Reactivity: agents must continuously monitor the environment in which they evolve and be able to react on changes occurred in it in due time for the reaction to be useful;

- Communication and social skills: agents interact with other agents and possibly 
humans by means of cooperation, coordination and negotiations [12];

- Proactivity: the agent does not respond only to changes in the environment in which it operates, but it is able to show a goaloriented behavior by taking the initiative;

- Mobility: degree of agents' migration in the network.

The technology behind the intelligent agents is a combination of techniques from artificial intelligence and systems development methodologies such as object oriented programming, allowing programs to learn from / to react to the environment. Intelligent agents interact with the environment through sensors and effectors.

An intelligent agent shall develop appropriate rules through explicit instructions provided by the user, by imitating user, by positive or negative feedback (response) received from the user and by the information obtained from interacting with other agents. For example, an intelligent agent for making instructional decisions allows visualization of the adaptive effect generated by the interaction of the components [13].

Research on problem solving using intelligent agents have revealed the existence of complex problems such as decision making and planning, that cannot be solved by isolated intelligent agents. Thus, MAS was proposed to solve such problems.

MAS operation is based on an infrastructure that provides the rules to be followed by the agents in order to communicate with each other and to understand each other.

\section{Adaptive e-Learning Systems}

Adaptive learning is defined as "the process of generating a unique learning experience for each learner based on the learner's personality, interests and performance in order to achieve goals such as learner academic improvement, learner satisfaction, effective learning process and so forth" [14], [15].

The whole idea of adaptive learning is that there exists no learning style that fits all types of learners' needs. There are two general approaches for adapting learning content [16], [17], [18] and the challenge of adaptive systems is to balance between these two different forms of adaptation: (1) adaptivity, which relates to the extent the system output is flexible based on some knowledge about the learner thus trying to adapt learning content with individuals' needs and (2) adaptability, which is system reliability in response to user modifiability focusing on delivering the most appropriate order of learning contents based on the learners' needs. The former is controlled by the system and is referred to as adaptation in content level while the latter is studentcontrolled and is called link-level adaptation [16], [17], [18], [19].

In e-Learning systems, the one-size-fits-all approach has led to learners' confusion [20]. Inevitably, adaptive learning has gained a great deal of attention in this area [21], [22].

Adaptive e-Learning systems have undergone considerable changes over the last decade [23].

The architecture of an e-Learning system defines the different ways of message transfer when agents are interacting with Web services of each system. One of the fundamental aspects of e-Learning is the control of users' actions, ie, adaptation of their preferences and performances. E-Learning systems which take account of this particularly important requirement are educational systems having double agent architecture (see Figure 1) or architecture with multiple agents (see Figure 2).

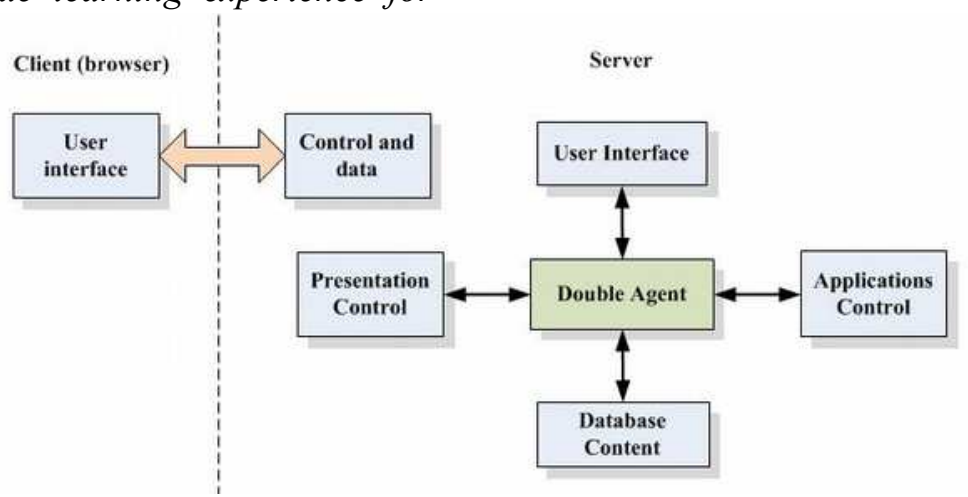

Figure 1. Double agent architecture 


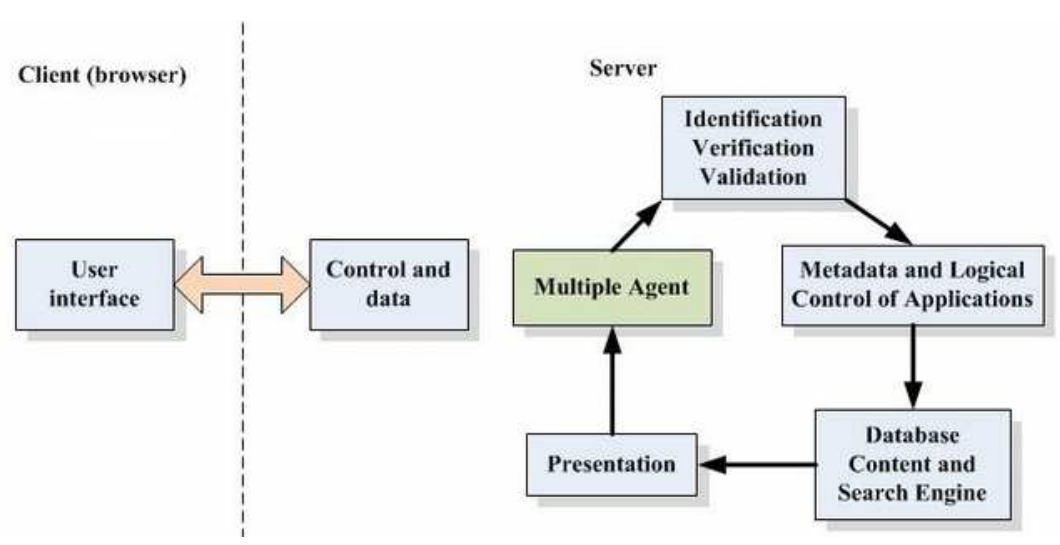

Figure 2. Architecture with multiple agents

The goal of adaptive e-Learning systems is to increase student performance by adjusting the content and methods of interaction of users with different interests, initial knowledge and skills. When faced with the task of defining user model, the developers of e-Learning platform are considering the theory of educational psychology and pedagogy. Four main approaches for adapting e-Learning are acro-adaptivity, aptitude-treatment interaction, micro-adaptive interaction and constructivecollaborative approaches. While the first three are limited to the content and learning itself, the latter integrates new paradigms in terms of adaptation. In addressing macro-adaptivity of e-Learning, the selection of training alternatives is based on the user's learning objectives, skills and achievements in curricular structure. Although it is an adaptive model, it is limited to a small number of features that a user might expose. Moreover, features of a user are preset so that any increase does not occur during the learning process [24].

\section{Multi-Agent Adaptive e-Learning Systems}

Adaptive e-Learning systems are based on multi-agent concepts [25], [26]. The agents' properties such as autonomy, preactivity, proactivity and cooperability can improve learning process quality by tailoring contents to learners' needs. Agents' application in ITS study is very useful as they bring the supportive classroom closer to distance learners and simulate the human-side of learning more naturally than any other controlled computerbased approach.

One of the trends of interactive teachinglearning systems is to incorporate components for generating a process of teaching-learning based on learner preferences and needs. This is a characteristic of Adaptive Educational Systems (AES), which requires intelligent agents for independent learning of the system and for communication between components.

Adapting to the needs of learners is a challenge in e-Learning systems. Learning is facilitated when:

- Students are engaged in solving real problems;

- Existing knowledge is activated as a basis for new knowledge;

- Students are asked to use new knowledge gained for solving problems and integrating them into their daily work.

Acquiring knowledge and the learning process need to be strengthened in order to incorporate flexibility and understanding the needs of the learner.

Of all the open source versions available on the Internet, Moodle is the most widely used eLearning platform.

Moodle approach is based on three main components: tutor (the word assigned to teacher in e-Learning), classroom used for the educational process and students (learners).

These components work together as follows:

- The tutor provides all information necessary to conduct the course. He organizes weekly activities or thematic content and introduces the theme topic, support resources and tools (files, documents, videos, audio, etc.) and activities that must be completed by students;

- Teaching-learning process is developed in the classroom and information obtained here are stored in a relational database, which is comprehensive and accessible through the user interface; 
- The student through the proposed activities, download or check the resources and interact with other learners in accordance with guidance from the tutor.

Moodle structure enables the provision of facilities in order to offer students different resources and activities and to facilitate interaction between students, between students and tutors and tutors and students. If there is no information about user preferences, navigation sequence, documents assessment and level of knowledge, the teaching learning process is generally developed for all members of the class.

An alternative to such problems is to focus Moodle on students' needs, trying to adapt the system to each of the students and to train them according to individual needs and learning style. For this reason, a structure that allows Moodle to be adaptable is needed.

The paper presents an architecture that provides adaptive and navigation facilities to intelligent agents associated with using different modules in Moodle.

\subsection{Moodle platform}

Moodle is an e-Learning platform, a Learning Content Management System (LCMS), which includes all the functions needed to manage learning contexts. Moodle allows collaboration between students and tutors and the transmission of knowledge between them. Moodle is developed on a modular, objectoriented structure, able to organize courses on different modules, encouraging a networked teaching and learning process.

Moodle e-Learning platform is an innovative tool to support the users' educational process in terms of valuing and developing their individual skills for online and distance learning.

It supports remote training so that users will have access to the relevant training materials when they wish, their progress indicators being monitored by tutors, and will receive support for online training through sessions with virtual classroom type.

\subsection{An adaptive logical architecture proposed for Moodle}

The objective of an e-Learning intelligent agent is to perform learning, communication functions, to provide independence between system components and to transmit the content to the user. Moreover, given characteristics and needs, the best way of providing the information generated in the process is decided.

The adaptive architecture of AES for Moodle proposed in this paper is a dynamic and multiagent structure that enables learning, communication and independence between system components using an intelligent agent for making instructional decisions.

This architecture has four principal modules: tutor module, student module, user interface module, and knowledge base. Each of the first three has an intelligent agent that performs tasks for each module [27].

The principal functions for each agent are:

- Tutor intelligent agent has didacticpedagogical functions and tutor modelling;

- Student agent carries out the creation of student models and information updating;

- User interface agent (student-tutor) determines the most appropriate interface for each user based on the hardware and software used for the connection;

- Instructional decision making agent communicates and interacts among agents and determines the best method of instruction for the final user.

In the knowledge base module, the development of one or more agents can be considered, depending on the way the information is structured.

Moodle contains basic information from tutors, students and content, but does not store the path of interactions between different actors. This can be improved by the inclusion of intelligent components, thus providing a personalized teaching-learning process.

The definition and implementation of intelligent agents as components for a Moodle virtual platform do not imply the disappearance of the main actors: professor and student.

For defining the intelligent agents for Moodle e-Learning platform it is necessary to determine the type of learning in accordance with the information available. Various components proposed for AES modules are based on an analysis of information available on the Moodle virtual platform that allows defining adaptation tasks necessary to acquire adaptive approach. Next, components and intelligent agents that will occur in adaptive 
architecture (see Figure 3) using the virtual platform Moodle as a base will be presented.

\subsection{Tutor module}

This module has a set of rules for adaptation and training. The module interacts with the system knowledge base and performs individualized teaching by user-friendly interfaces. This module is responsible for the proper design of the course for each student, according to the performance of a student.

The intelligent agent associated with this module is the intelligent agent for tutor modelling that must fulfil the following functions:

- Didactical-pedagogical function (teaching style): by considering the students and the response to a particular style, the agent will be able to classify what form of teaching is the most accepted by a particular student profile. Thus, when the agent has learned, it can choose the most appropriate style for each user based on his profile;

- Tutor Modelling (implementation of content): This process begins with a modeling process which collects information about proposed activities and resources for students and their success rates. Based on this experience, the agent learns the best way of implementing the content.

- Retrieval and storage of information from / into the knowledge base module.

After reviewing this information, tutor models can be defined that can be applied to established models of students. Tutor models may vary depending on the level of learning and the experience gained by the agent. This allows defining more specific models that can be best adjusted to a particular type of student.

\subsection{Knowledge base module}

This module has various information sources such as: student's personal data, interaction data, environment data, and information on instructional design.

The Intelligent agent associated with this module uses the initial knowledge of the system to obtain a conclusion or new knowledge using various sources of information.

\subsection{Student module}

In an adaptive architecture, students generate the underlying information for adaptation. This actor turns into an independent module in which, based on the students' characteristics, needs and preferences, different models are generated.

The intelligent agent for student modelling performs certain functions in this module, such as:

- Creating Student Models: this function is based on a previous model, where explicit and implicit variables are defined. The student models include navigation environments, learning styles, learning levels, levels of cooperation and interaction. The agent will be able to classify the

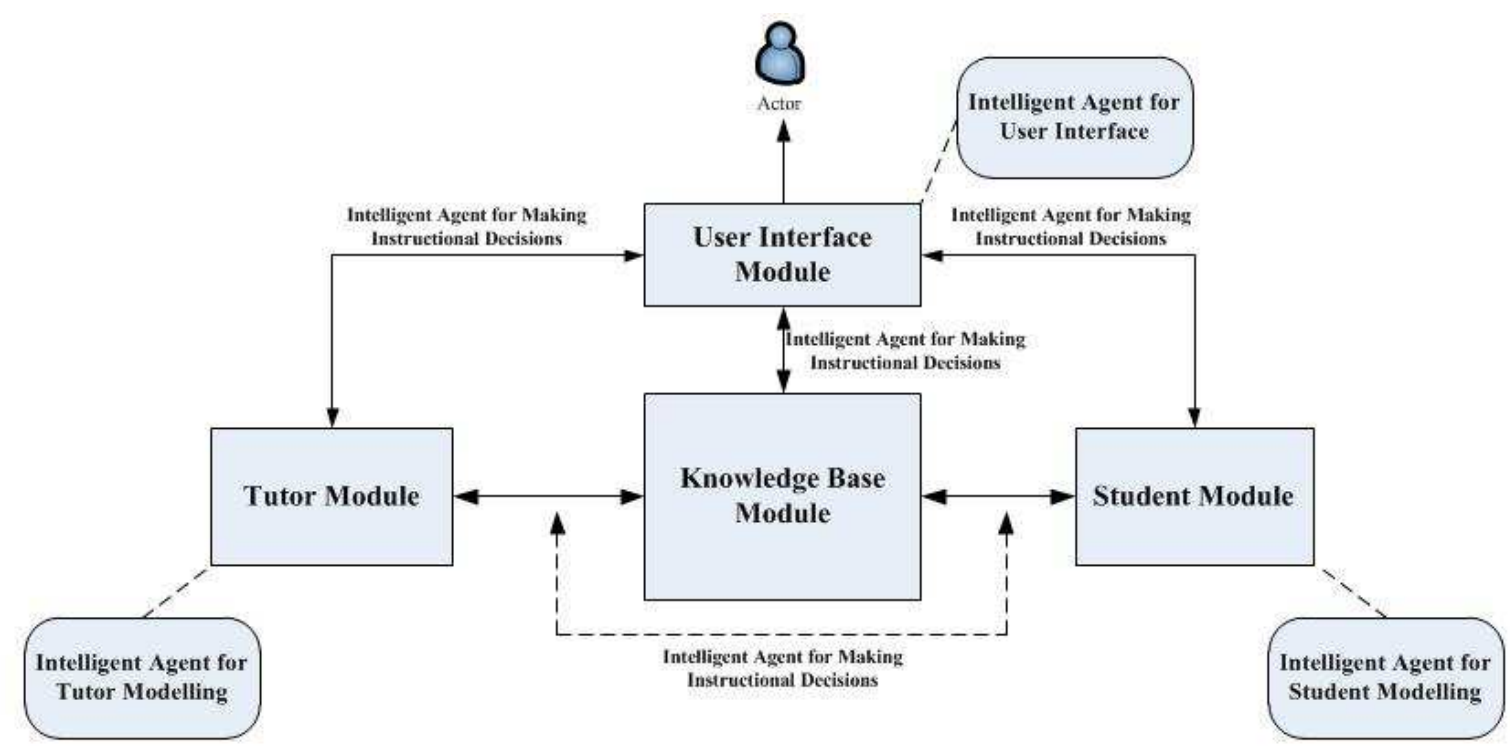

Figure 3. Moodle's Adaptative Logical Architecture 
different profiles depending on the student model that they have similarities;

- Update information: student information is updated by the agent responsible for monitoring student activities and actions in the system. After comparing information, the agent will change the model assigned to the student (if necessary) and will determine student progress;

- Interaction with the knowledge base: this is achieved through the intelligent agent for making instructional decisions. Data of each student profile are retrieved from the Knowledge Base and are saved in it when the student is identified in the system or when he leaves the system.

\subsection{Interface module for users}

In this module, characteristics such as the type of browser used, type of device used for access, and the available connections are identified.

Intelligent agent for user interface determines the the most appropriate type of system interface to be offered to each user based on the hardware and software used for the connection.

Software connection tools and equipment used are different for each user and for this reason, each has different presentation needs. The agent must learn these conditions and determine the most appropriated type of system interface. This learning can be achieved when students can interact with the provided interface where identification is accepted or refused.

The user model agent performs the following functions:

- Creates student models based on a previous model;
- Categorizes student profiles;

- Monitors users while they interact with the e-Learning platform;

- Updates student information.

\subsection{Intelligent Agent for Making Instructional Decisions}

The objective of this intelligent agent is to fulfil instructional decisions as well as to transmit the content to the user. Furthermore, it decides the best way to offer information generated in this process. This agent receives information through the module for user interface, specifically the one generated by the agent for interface. It is the first to have contact with the user because it communicates with the module for students, where the information regarding the profile (stored in the knowledge basis) and the student model (stored in the student module) are restored. They are then sent to the tutor module where, according to the tutor model assigned for the student model, the most appropriate instructional design is offered. Finally, the agent displays the results of this process to the user. At this stage, the intelligent agent chooses how to show through the interface the content generated based on the style best suited to the learning process of the student. The intelligent agent has the function of restoring, transmitting, and sending information through the different modules of the system.

The structure and the process carried out through intelligent agent for making instructional decision are illustrated in Figure 4.

Intelligent agent for making instructional decision has different inputs which are derived from the modules: user interface, students,

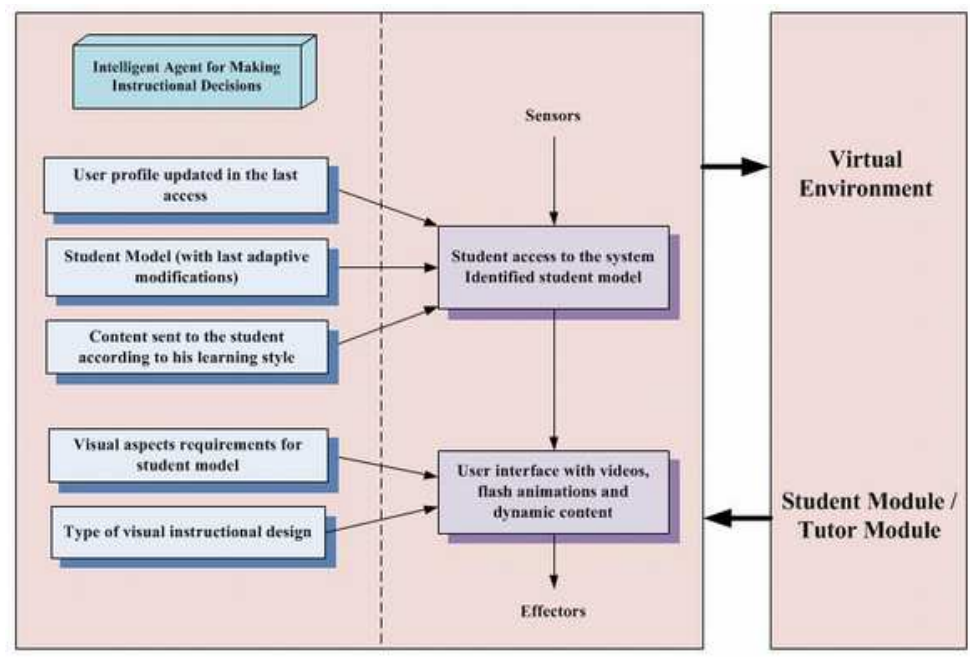

Figure 4. Example of the structure of intelligent agent for making instructional decision 
knowledge basis, and tutor. They generate communication and reception of information through the agents that interact inside each module. The changes generated by such agents are received through the sensors of the intelligent agent for making instructional decision; they are processed in the different action-reaction rules (rules of inference) of the agent. Finally, the resulting actions are sent through the effectors to the components that have generated the environment inputs of intelligent agent for making instructional decision and, in the same way, are stored in the agent memory (states) for its self-learning.

\subsection{Functional description of architecture for multi-agent adaptive e-learning system}

The intelligent agent for making instructional decision is responsible for selecting the teaching strategy according to the current learning style of the student. It is used to filter the learning objects that will be displayed.

When all teaching strategies related to the learning style of the student have been current used, the agent will be able to change their current style.

Below is presented the functional description of architecture for Multi-Agent Adaptive eLearning System:

1. For system security, each user must have an account. User accounts are created by the system administrator. After logging in, the user can view the available activities (lessons, courses, tests), information blocks, and according to user rights, he can add resources, activities and blocks. The user has the possibility to edit his profile;

2. Web navigation can be done using the menus on the left or on the top of the page (see Figure 5);

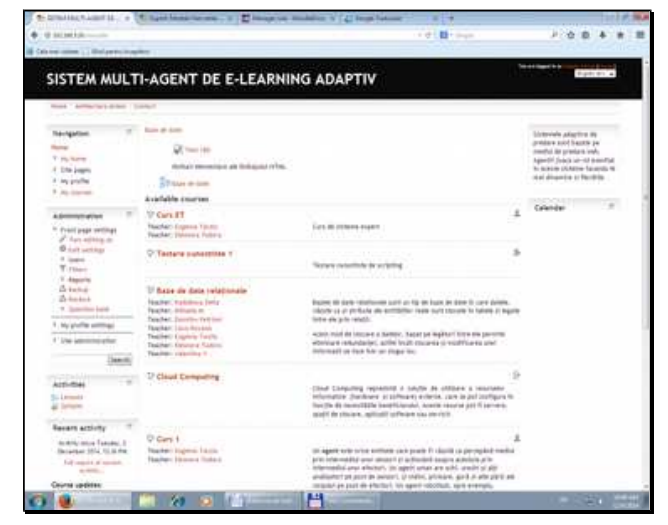

Figure 5. Navigation page
3. The entire activity in Moodle is organized around courses. The tutor, who wants to add a course for students, uses the button "Add new course." By acting this button the course is created and appears the window "Edit course settings" in which will be included full name and short name of the course with a brief description of it;

4. The activities are interactive materials and enhance the participation and involvement of the students in the educational process. To add an activity, select the course and press the button "Add activity or resource";

5. The quiz allows the professor to ask the students a multiple choice question and then collect their answers. The quiz is useful for initial testing within a lesson, to see the students level;

6. The database allows students to create, display and query a collection of articles about a particular topic;

7. The forum is a tool that enables asynchronous communication. The tutor creates forum and then invite students to subscribe to it. Students will receive an e-mail notification, will access the forum and will post their own opinion on the subject requested. Messages can be posted any time, students prefer such activity because they are not pressed for time, thinking before posting messages;

8. The test is the activity that can be considered the most important, used for grading of students level in an objective manner. The test is a structure made up of items and aims to perform self assessment of an amount of knowledge or skills. A test is created in the course by selecting the button "Test" from the list of activities;

9. Pressing the button "Send all and end" has the effect of sending the test for scoring. The student will get the grade obtained and the feedback with right and wrong answers;

10. Finally, the results, the time required to execute the test and the grade obtained by the student are displayed. After developing a test, the turor must verify the presentation mode on the screen, as it will be seen by student, to check the content, the accuracy of response and the presentation.

The intelligent agents choose the way of presenting the content through the interface, based on the most appropriated style for the student's learning process. 
Currently, the tutor and student agents have been developed.

\section{Conclusions}

A combination of the advantages of modern AES, such as adaptability and personalization with the key features of traditional LMS which are integration, re-use and an adequate set of services for both learners and teachers provided by one system is necessary. Combining intelligent agents with an open source eLearning platform is being proposed offering profiling and personalization services for the teacher and student while at the same time adapts the educational content and tools in the basis of the user's profile.

In order to realize this combination the paper describes a solution based on an open source traditional LMS and suggests the upgrading of its capabilities focusing on adaptation and personlization. Moodle virtual platform is the most suitable for extending to an adaptive solution. It offers courses, content, as well as communication and interaction tools to all students as well as differences for their individual characteristics or preferences. This aspect can be improved by including intelligent components, thus providing a personalized teaching-learning process.

\section{Acknowledgements}

This material is based upon work supported by the Romanian National Education Ministry under Grant No. PN 09-230605/2014 „Perceptual Modeling and mechanisms for generating actions for developing autonomous agents".

\section{REFERENCES}

1. FLOREA, A., Introduction to MultiAgent Systems, International Summer School on Multi-Agent Systems, Bucharest, 1998, pp. 1-11.

2. SHOHAM, Y., Agent-oriented Programming, Artificial Intelligence, Vol. 60, 1993, pp. 51-92.

3. WOOLDRIDGE, M., N. R. JENNINGS, Agent Theories, Architectures, and Languages, Wooldridge and Jennings, eds. Intelligent Agents, Springer Verlag, 1995, pp. 1-22.
4. WOOLDRIDGE, M., Agent-based Software Engineering, IEEE Proceedings Software Engineering, vol. 144, issue 1, 1997, pp. 26-37.

5. FRANKLIN, S, A. GASSER, Is It an Agent, or Just a Program?: A Taxonomy for Autonomous Agents, Muller, Wooldridge, and Jennings, eds. Intelligent Agents III. Agent Theories, Architectures, and Languages. Springer Verlag, 1997, pp. 21-35.

6. DRAGOMIR, E. G., Development of a Multi-Agent-Based Simulation System for Air Quality Analysis, Studies in Informatics and Control, ISSN 1220-1766, vol. 23, issue 4, 2014, pp. 371-381.

7. WOOLDRIDGE, M., An Introduction to Multi-agent Systems (2nd ed.), Wiley Publishing, 2009, ISBN 0470519460, 9780470519462.

8. FERBER, J., Multi-agent Systems: an Introduction to Distributed Artificial Intelligence, Addison-Wesley, Reading (1999).

9. HAYES-ROTH, B., An Architecture for Adaptive Intelligent Systems, Artificial Intelligence. vol. 72, 1995, pp. 329-365.

10. KOEDINGER, K., J. ANDERSON, W. HADLEY, M. MARK, Intelligent Tutoring Goes to the Big City, Proceedings of the International Conference on Artificial Intelligence in Education, Jim Greer (Ed). AACE: Charlottesville, VA, 1995, pp. 421-428.

11. WEISS, G., Multiagent Systems - A Modern Approach to Distributed Modern Approach to Artificial Intelligence, The MIT Press, Cambridge, Massachusetts, 1999.

12. COHEN, P.R., CHEYER, A.J., WANG, M., BAEG, S.C., An open agent architecture, O. Etzioni, editor, Proceedings. of the AAAI Spring Symposium Series on Software Agents, Stanford, California, March. American Association for Artificial Intelligence, 1994, pp. 1-8.

13. JARA-ROA, D., P. VALDIVIEZO-DÍAZ, M. AGILA-PALACIOS, C. SARANGOLAPO, M. RODRIGUEZ-ARTACHO, An Adaptive Multi-Agent based Architecture for Engineering Education, IEEE EDUCON Education Engineering 
2010, The Future of Global Learning Engineering Education, E-ISBN: 978-14244-6570-5, pp. 217-222.

14. MONOVA-ZHELEVA, M., Adaptive Learning in Web-based Educational Environments, Cybernetics and Information Technologies, vol. 5, issue 1, 2005, pp. 44-55.

15. ROSMALEN, P., H. VOGTEN, R. VAN ES, H. PASSIER, P. POELMANS, K. KOPER, Authoring a Full Life Cycle Model in Standards-based Adaptive eLearning, Educational Technology \& Society, vol. 9, issue 1, 2006, pp. 72-83.

16. OLFMAN, L., M. MANDVIWALLA, Conceptual Versus Procedural Software Training for Graphical User Interfaces: A Longitudinal Field Experiment, MIS Quarterly, vol. 18, iss. 4, 1994, pp. 405-426.

17. PAPANIKOLAOU, K., M. GRIGORIADOU, G. MAGOULAS, H. KORNILAKIS, Towards New Forms of Knowledge Communication: The Adaptive Dimension of a Web-based Learning Environment, Computers \& Education, vol. 39, issue 4, 2002, pp. 333-360.

18. SAMUELIS, L., Notes on the Components for Intelligent Tutoring Systems, Acta Polytechnica Hungarica, vol. 4, issue 2, 2007, pp. 77-85.

19. MAGOULAS, G., K. PAPANIKOLAOU, M. GRIGORIADOU, Adaptive Webbased Learning: Accommodating Individual Differences through Systems Adaptation, British Journal of Educational Technology, vol. 34(4), 2003, pp. 511-527.

20. YAGHMAIE M., A BAHREININEJAD, Context-aware Adaptive Learning System using Agents, Expert Systems with Applications, vol. 38, 2011, pp. 3280-3286.
21. WANG, T., K. WANG, Y. HUANG, Using a Style-based Ant Colony System for Adaptive Learning, Expert Systems with Applications, vol. 34, issue 4, 2008, pp. 2449-2464.

22. YANG, Y., C. WU, An Attribute-based Ant Colony System for Adaptive Learning Object Recommendation, Expert Systems with Applications, vol. 36, issue 2, 2009, pp. 3034-3047.

23. DE BRA, P., Adaptive Hypermedia, H. H. Adelsberger, Kinshuk, J. M. Pawlowski, D. Sampson (Eds.), Handbook on Information Technologies for Education and Training, Springer-Verlag, 2008, pp. 29-46.

24. FITRE, A., C. V. BRATU, C. CĂLIN, Researching the Psychology of Cognitive Style and Learning Style: Is There Really a Future, Intelligent Computer Communication and Processing, IEEE 5th International Conference, 27-29 August, 2009, pp. 35-38.

25. CANALES, A., A. PENA, R. PEREDO, H. SOSSA, A. GUTIERREZ, Adaptive and Intelligent Web based Education System: Towards and Integral Architecture and Framework, Expert Systems with Applications, vol. 33(4), 2007, pp. 1076-1089.

26. CHEN, C., Intelligent Web-based Learning System with Personalized Learning Path Guidance, Computers \& Education, vol. 51(2), 2008, pp. 787-814.

27. VALDIVIEZO, P., I. JARA, M. AGILA, P. SARANGO, R. PESÁNTEZ, M. RODRIGUEZ-ARTACHO, A Multi-Agent Architecture to Provide Adaptive Learning Content in Moodle, 8th Mexican International Conference on Artificial Intelligence, Guanajuato, Mexico, November 9-13, 2009. 